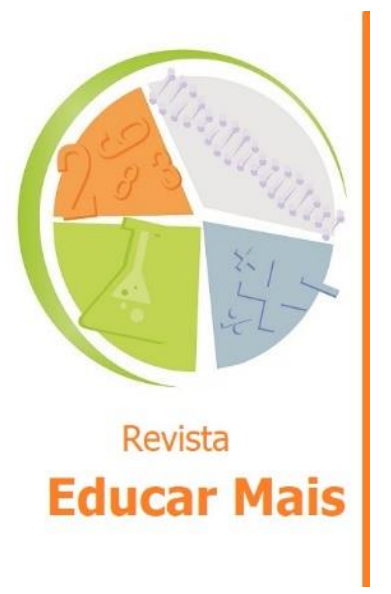

\title{
Um pequeno passo: uma sessão de planetário para as Séries Iniciais do Ensino Fundamental
}

\author{
A small step: a fulldome planetarium show for Early Grades of \\ Elementary School
}

Un pequeño paso: una sesión de planetario para los Primeros Grados de la Escuela Primaria

Cecília Petinga Irala ${ }^{1}$; Rafael Kobata Kimura ${ }^{1}$; Guilherme Frederico Marranghello ${ }^{1}$

\section{RESUMO}

Este trabalho apresenta a avaliação da criação de uma sessão de planetário que versa sobre a Lua (fases, eclipses e corrida espacial) para crianças das séries iniciais do ensino fundamental. Dada a escassez de trabalhos voltados à pesquisa em ensino e divulgação de ciências em planetários, o artigo busca contribuir para o desenvolvimento de pesquisas na área ao também abranger uma breve revisão histórica e apresentar uma sucinta fundamentação teórica sobre pesquisa em planetários. A sessão foi criada considerando aspectos culturais da astronomia e fundamentada em diversos trabalhos que, pontualmente, orientavam a construção de sessões de planetário. Para avaliar a sessão, foi conduzida uma pesquisa quanti-qualitativa, com testes padronizados e entrevistas conduzidas pelo método da memória estimulada. Os resultados indicam que a sessão conseguiu desmistificar algumas ideias equivocadas que as crianças tinham sobre a Lua e que associar lendas aumenta a conexão afetiva do espectador com a sessão. Considerando a escassa literatura nacional sobre a produção de sessões de planetário, esperamos que este trabalho contribua significativamente para o desenvolvimento de pesquisas na área.

Palavras-chave: Planetários; Sessão de Planetário; Divulgação Científica.

\begin{abstract}
This paper presents the evaluation of fulldome planetarium show creation that deals with the Moon (phases, eclipses and space race) for children in the initial grades of elementary school. Given the scarcity of research papers in science teaching and science communication for planetariums, this article intends to contribute to the development of research in this area by also covering a brief historical review and presenting a succinct theoretical basis on planetarium research. The show was created taking into account cultural aspects of astronomy and was based on several small fragments of different works that guided the construction of fulldome planetarium shows. To evaluate the show, a quantitative and qualitative research was conducted, with standardized tests and interviews conducted by the stimulated memory method. The results indicate that the show demystifies some misconceptions that children had about the moon and that associating legends increases the expectator's affective connection with the show. Considering the scarce national literature on the production of planetarium sessions, we hope that this work contributes significantly to the development of research in the area.
\end{abstract}

Keywords: Planetarium; Fulldome Planetarium Show; Science Communication.

\footnotetext{
${ }^{1}$ UNIPAMPA - Universidade Federal do Pampa, Bagé/RS - Brasil.
} 


\section{RESUMEN}

Este trabajo presenta la evaluación de la creación de una sesión de planetario que se ocupa de la Luna (fases, eclipses y carrera espacial) para niños de los grados iniciales de la escuela primaria. Dada la escasez de trabajos destinados a la investigación en la enseñanza y la difusión de la ciencia en planetarios, el artículo busca contribuir al desarrollo de la investigación en el área al cubrir también una breve revisión histórica y presentar una base teórica sucinta sobre la investigación en planetario. La sesión fue creada considerando aspectos culturales de la astronomía y basada en varios trabajos que, ocasionalmente, guiaron la construcción de sesiones de planetario. Para evaluar la sesión, se realizó una investigación cuantitativa-cualitativa, con pruebas estandarizadas y entrevistas realizadas por el método de memoria estimulada. Los resultados indican que la sesión logró desmitificar algunas de las ideas erróneas que los niños tenían sobre la Luna y que asociar leyendas aumenta la conexión emocional del espectador con la sesión. Considerando la escasa literatura nacional sobre la producción de sesiones de planetario, esperamos que este trabajo contribuya significativamente al desarrollo de la investigación en el área.

Palabras clave: Planetarios; Sesión de Planetario; Divulgación Científica.

\section{INTRODUÇÃO}

Planetários são espaços usualmente caracterizados como espaços de educação não-formal (LANGHI, NARDI, 2009). Isto se deve, principalmente, ao fato destes locais, assim como museus, aquários ou jardins botânicos, receberem um grande número de visitantes fora de uma organização escolar. Mas o que podemos dizer de espaços como o Planetário da Unipampa, no qual mais de $95 \%$ do público é composto por turmas escolares que agendam suas visitas, escolhem a temática da sessão e inserem a visita como parte de seus planos de ensino? O Planetário da Unipampa, pela facilidade de acesso, é quase uma extensão do espaço escolar, tal como um laboratório ou uma biblioteca. Por esta razão, apesar do planetário ser considerado um espaço não-formal de educação, não podemos desprezar sua estreita ligação com as ações escolares, em uma relação de proximidade com a educação formal (MARANDINO, 2017).

Para atender à demanda dos professores que visitam o planetário, da secretaria de educação ou dos documentos oficiais que orientam os conteúdos de astronomia nos currículos dos mais diversos níveis de ensino, faz-se necessária a aquisição e/ou produção de um número considerável de sessões. Ao adquirir sessões, lembrando que a grande maioria é produzida no hemisfério norte, um planetário deve se atentar aos conteúdos e também aos valores culturais. Estas sessões adquiridas também são, em grande parte dos casos, altamente focadas no público em geral, preterindo turmas escolares. Ainda existem outros limitantes, como a orientação do planetário, resolução e sistema de projeção, dentre outros. Ante a necessidade de termos sessões que se adaptassem ao nosso contexto, optamos por desenvolver nossas próprias sessões.

Ao buscar referenciais que orientassem a construção de sessões, descobrimos uma escassez quase completa na literatura nacional. Também não encontramos na literatura internacional, um referencial que orientasse a construção de sessões de planetário; encontramos somente uma grande quantidade de trabalhos que, pontualmente, foram contribuindo para a construção da sessão. 
Este artigo tem como foco principal apresentar a avaliação da criação de uma sessão de planetário que versa sobre a Lua (fases, eclipses e corrida espacial) para crianças das séries iniciais do ensino fundamental, buscando analisar os impactos causados pela sessão nos estudantes, tanto do ponto de vista do conteúdo ensinado, como do ponto de vista afetivo. Considerando ainda a escassez de pesquisas nacionais sobre planetários, orientamos a escrita deste artigo de forma mais ampla e abrangente, acreditando que este possa ser considerado como uma referência para futuros trabalhos. Desse modo, este artigo está organizado da seguinte forma: na seção 2, apresentamos uma revisão histórica dos planetários e da pesquisa educacional desenvolvida nestes espaços; apresentamos, na seção 3, uma discussão sobre a pesquisa nacional; a construção da sessão de planetário intitulada "Um Pequeno Passo" é descrita na seção 4, enquanto a metodologia de pesquisa é discutida na seção 5, deixando a análise dos resultados para a seção 6 .

\section{OS PLANETÁRIOS}

O primeiro planetário foi construído pela empresa Zeiss e instalado na própria fábrica, no ano de 1923, na cidade de Jena. Segundo Vieira (2013), o projeto teve início em 1913, quando o diretor do Deustches Museum procurava por uma nova atração. O projeto teve que ser interrompido durante a Primeira Guerra Mundial, sendo finalizado 10 anos depois, com a construção do projetor e do domo de 16 metros no teto da fábrica da Zeiss. A receptividade foi positiva, conforme relato de Vieira (2013, p.11): "As demonstrações causaram um grande impacto indicando o sucesso do empreendimento, evidenciado pela epígrafe 'A maravilha de Jena'".

Em seguida, o projetor foi levado para o museu, demonstrando, segundo Vieira (2013) os movimentos da Terra, do Sol, da Lua e dos planetas, Sol da Meia Noite, identificação das estrelas e constelações. A empresa Zeiss comercializou, até 1939, outro equipamento do Modelo I e mais 25 equipamentos do Modelo II, que permitia a visualização das constelações dos dois hemisférios.

O planetário chegou à América, mais precisamente em Chicago (Planetário Adler) em 1930 (WEBB, 2013). A América Latina recebeu seu primeiro planetário em Montevidéu (Planetário Agrimensor Germán Barbato), inaugurado em 1955 (CASTELAR, 2013), sob uma cúpula de 18 metros de diâmetro. Já o primeiro planetário brasileiro foi inaugurado em São Paulo, em janeiro de 1957 (VARELLA, 2013).

Esta brevíssima história dos planetários, iniciada na Alemanha, passando pelos EUA, chegando na América Latina e, finalmente, no Brasil está descrita em mais detalhes na Planetaria, a revista oficial da Associação Brasileira de Planetário. Esta revista nacional é dedicada à divulgação de material ligado ao tema, entretanto, é importante salientar que esta não é uma publicação na qual necessariamente se encontrarão artigos com resultados de pesquisa. Trata-se mais de uma publicação com caráter de divulgação científica de grande relevância para o desenvolvimento, socialização e troca de experiência na comunidade de planetaristas. É nesta revista que encontramos artigos falando sobre o trabalho com planetários infláveis (RESENDE, 2014), sobre projetos de grande importância, como o Projeto Eratóstenes (LANGHI, 2014) e sobre temas mais específicos relacionados a planetários, como os trabalhos de Langhi, Vilaça e Pereira (2015), "Qual o nosso papel na Educação?", Gonçalves (2015), "Planetário, o transformador", Barros e Langhi (2015), "Formação de Planetaristas", Honorata (2016), "O Planetário da UFSC e o céu Tupi-Guarani" e Berglund (2018), "Valorizando as Sessões ao Vivo". 
Para falar da pesquisa sobre o Ensino de Astronomia em planetários é necessário nos referirmos ao financiamento americano para a construção de planetários durante a corrida espacial, no Ato Educacional de Defesa Nacional de 1958. Foi através deste forte financiamento que centenas de planetários foram construídos nos EUA (SLATER, TATGE, 2017). Um financiamento gigantesco de apoio à educação requeria resultados, e foi assim que a pesquisa sobre a importância de planetários no ensino de astronomia também cresceu. O livro de Slater e Tatge (2017) apresenta uma perspectiva histórica da evolução da pesquisa sobre planetários, essencial para quem deseja desenvolver trabalhos de pesquisa na área. Não é nossa intenção refazer este percurso histórico, mas é necessário salientar alguns aspectos importantes.

Plummer et al. (2015) discutem as possibilidades de pesquisa envolvendo planetários e, através da Figura 1, resumem algumas das ações possíveis dentro e fora do domo, em comparação com ações mais ou menos estruturadas, considerando-as como educação formal e não-formal.

Figura 1 - Quadrantes da pesquisa em educação em planetários.

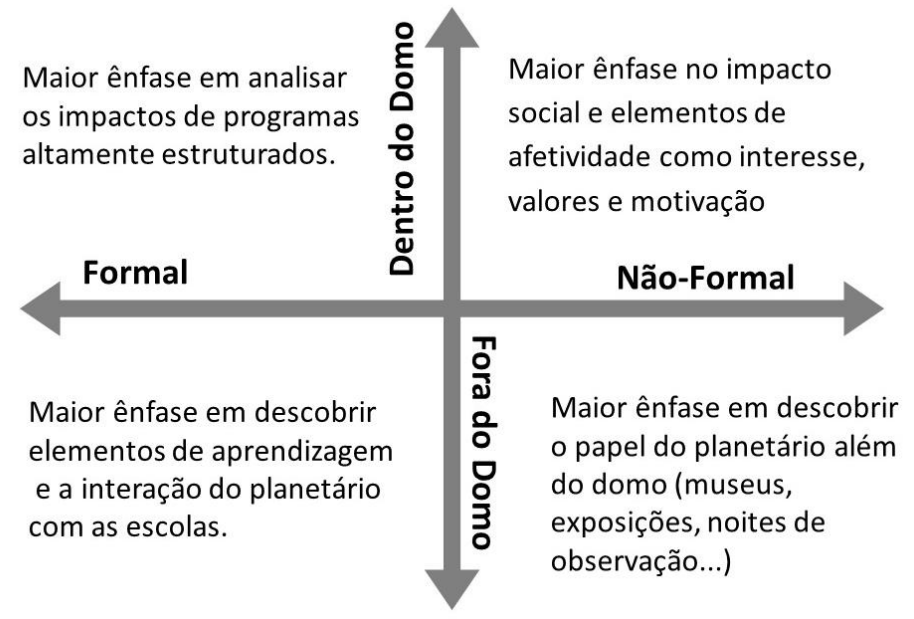

Fonte: Adaptado de Plummer et al. (2015).

Desta forma, a pesquisa relacionada a planetários pode englobar uma grande variedade de assuntos, incluindo a formação inicial e continuada de professores, a formação de monitores e planetaristas, o desenvolvimento de materiais/sessões acessíveis a todo o público, métodos e abordagens para o ensino de Astronomia que complementem as sessões de cúpula, o ensino de Astronomia para crianças da pré-escola, séries iniciais, finais, médio, EJA, adultos, terceira idade, representações utilizadas nas sessões, aprendizagem de conceitos astronômicos, impactos sociais dos planetários, estudo do público que visita o planetário e muito mais.

Para este trabalho, trazemos uma discussão apresentada por Slater e Tatge (2017), ao separar a discussão sobre a pesquisa em planetários no período de ouro dos equipamentos opto-mecânicos e após o surgimento da era digital. Os autores, ao comparar estes períodos, percebem também uma mudança com relação às publicações. A primeira delas está relacionada ao tipo de publicação e, a segunda, às características das pesquisas.

No período que dura até o início da década de 1990, a maioria das pesquisas sobre planetários, nos EUA, estava descrita no que os autores chamam de "grey literature", ou seja, em reports e teses (88\%). Uma produção inferior ocorria em periódicos avaliados por pares (12\%). No período posterior, 
o número de artigos avaliados por pares chega a $62 \%$ do total de publicações, mostrando uma mudança no perfil da pesquisa sobre planetários nos EUA.

Os principais métodos de pesquisa eram quantitativos (73\%), enquanto métodos qualitativos (15\%) ou mistos (12\%) representavam uma porção menor dos trabalhos, no período que antecede 1990. Já no período posterior, a pesquisa puramente quantitativa representa apenas $30 \%$ do total, frente a $49 \%$ de trabalhos que utilizaram métodos mistos e $21 \%$ que utilizaram métodos qualitativos.

Um estudo mais amplo ainda discute os principais aspectos estudados em tais pesquisas, onde e por quem estes trabalhos foram realizados, nível de ensino do grupo avaliado e conteúdo abordado, além de aspectos afetivos, dentre outros. Esta mudança de paradigma na pesquisa sobre o ensino de Astronomia nos planetários apresenta correspondentes na pesquisa em ensino de ciências como um todo, mas também apresenta características destacadas devido à janela de possibilidades abertas pelos planetários digitais.

Ainda, a pesquisa em planetários pode envolver uma grande e diversificada classe de pesquisas, com estudos comparativos com a sala de aula (ZIMMERMAN, SPILLANE, REIFF, 2014), aprendizagem em anos iniciais (PLUMMER, 2009), estudos de conceitos específicos (TURK, KALKAN, 2015), comparação entre dois programas/sessões (MALLON, BRUCE, 1982) e muito mais.

\section{A PESQUISA NACIONAL}

Este trabalho se propõe não apenas a avaliar a sessão de planetário intitulada "Um Pequeno Passo", mas também a contribuir de forma significativa para futuras pesquisas sobre planetários. A necessidade de pesquisas na área pode ser apresentada pela baixíssima produção nacional sobre o tema, estando esta caracterizada de forma similar àquela que ocorria nos EUA entre as décadas de 1960 e 1990, conforme já demonstrado pelo trabalho de Freitas, Germano e Aroca (2014).

Com a finalidade de avaliar a contribuição nacional às pesquisas em planetários, realizamos uma busca no portal de periódicos CAPES $^{2}$ e no Banco de Teses e Dissertações sobre Educação em Astronomia ${ }^{3}$ pela palavra-chave "planetário" no título do trabalho e no resumo, já excluindo aqueles não relacionados ao tema.

Encontramos apenas uma tese de doutorado versando sobre uma pesquisa empírica relacionada aos planetários. O trabalho de Leonardo Marques Soares (2017) discute a Etnoastronomia, interculturalidade e formação docente nos planetários do Espaço do Conhecimento UFMG e do Parque Explora, sendo assim, uma referência de grande valor para futuros trabalhos.

Ainda no contexto do que foi chamado por Slater e Tatge (2017) como grey literature, encontramos alguns poucos trabalhos na forma de dissertação de mestrado. O primeiro deles, um projeto de intervenção nos espaços de exposição do planetário do Parque do Ibirapuera (ELIAS, 2006), traz uma pesquisa sobre atividades fora do domo, conforme caracterizado por Plummer et al. (2015).

Encontramos pesquisas que tratam da relação entre o planetário e a escola, como nos trabalhos de Lima (2014), Borges (2017) e Silva (2017), destacando, em especial, o trabalho de Resende (2017),

\footnotetext{
2 www.periodicos.capes.gov.br

3 www.btdea.ufscar.br
} 
que traz uma excelente discussão, apontando justificativas, dificuldades e propostas para promover a interação entre o planetário e a escola. Em seu trabalho, a autora apresenta preocupação com a pouca interação entre estes ambientes de educação que, em princípio, são complementares.

Ainda falando sobre a relação planetário-escola, mas com uma abordagem voltada mais especificamente para a interdisciplinaridade, podemos mencionar os trabalhos de Oliveira (2010) e Rosa (2015). A formação de professores é abordada por Martins (2009), Santos (2015) e Yano (2017).

Por fim, apenas dois trabalhos foram encontrados sobre a construção de sessões de planetário. 0 primeiro, "Construção de uma sessão de cúpula para o ensino de Física em um Planetário" (ROMANZINI, 2011), com um objetivo bem direcionado à Educação Formal, enquanto o segundo, "Construção de uma sessão de planetário para público geral com a temática 'interações Terra-Sol"' (FREITAS, 2015) traz uma abordagem oposta, no sentido de que a sessão é direcionada à Educação Não-Formal.

Desta forma, os trabalhos publicados na forma de dissertações e teses estão resumidos em um período de pouco mais de uma década (2006-2017), em um número reduzido (15). Apesar de destacarmos o aumento no número de dissertações produzidas no ano de 2017 (6), ressaltamos que apenas duas pesquisas foram conduzidas para investigar a construção de sessões de planetário. $A$ Figura 2 reproduz o número de dissertações e teses produzidas no Brasil.

Figura 2 - Número de dissertações e teses com o tema "Planetário" produzidas no Brasil.

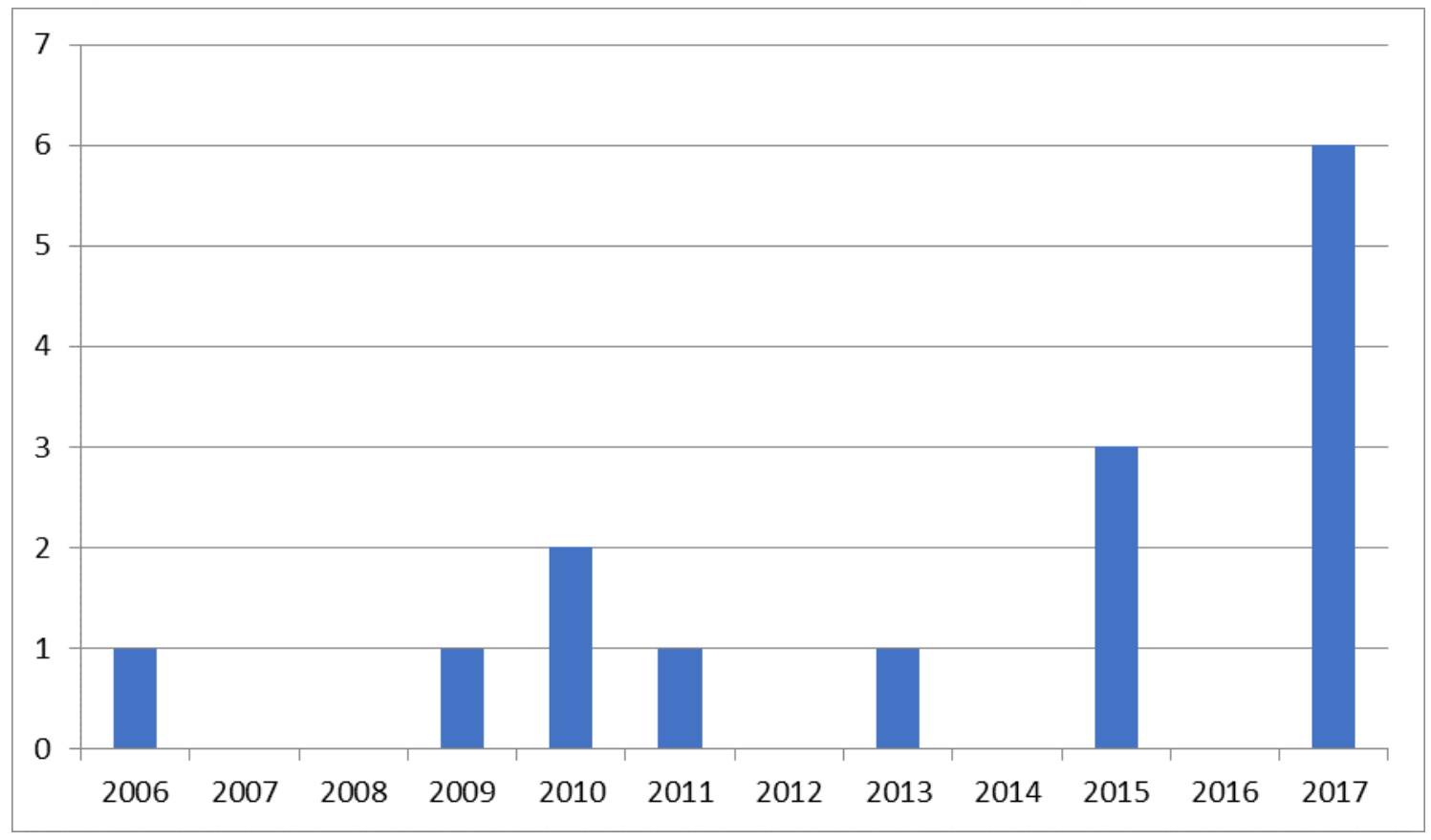

Fonte: Autores

Conduzimos também uma busca nas publicações dos eventos Simpósio Nacional de Educação em Astronomia (SNEA), Simpósio Nacional de Ensino de Física (SNEF) e Encontro Nacional de Pesquisa em Ensino de Ciências (ENPEC), buscando pela palavra-chave "planetário", somente no título. Para efeito de comparação, a Figura 3 apresenta o número de teses e dissertações ao lado do número de artigos publicados em anais de eventos. No período de 2011 a 2018, encontramos 39 trabalhos apresentados nos eventos mencionados, sendo que 23 destes trabalhos foram apresentados no SNEA, configurando o evento como um importante espaço de discussão sobre a temática. 
Figura 3 - Número de teses e dissertações sobre planetários comparado ao número de artigos publicados em atas de eventos.

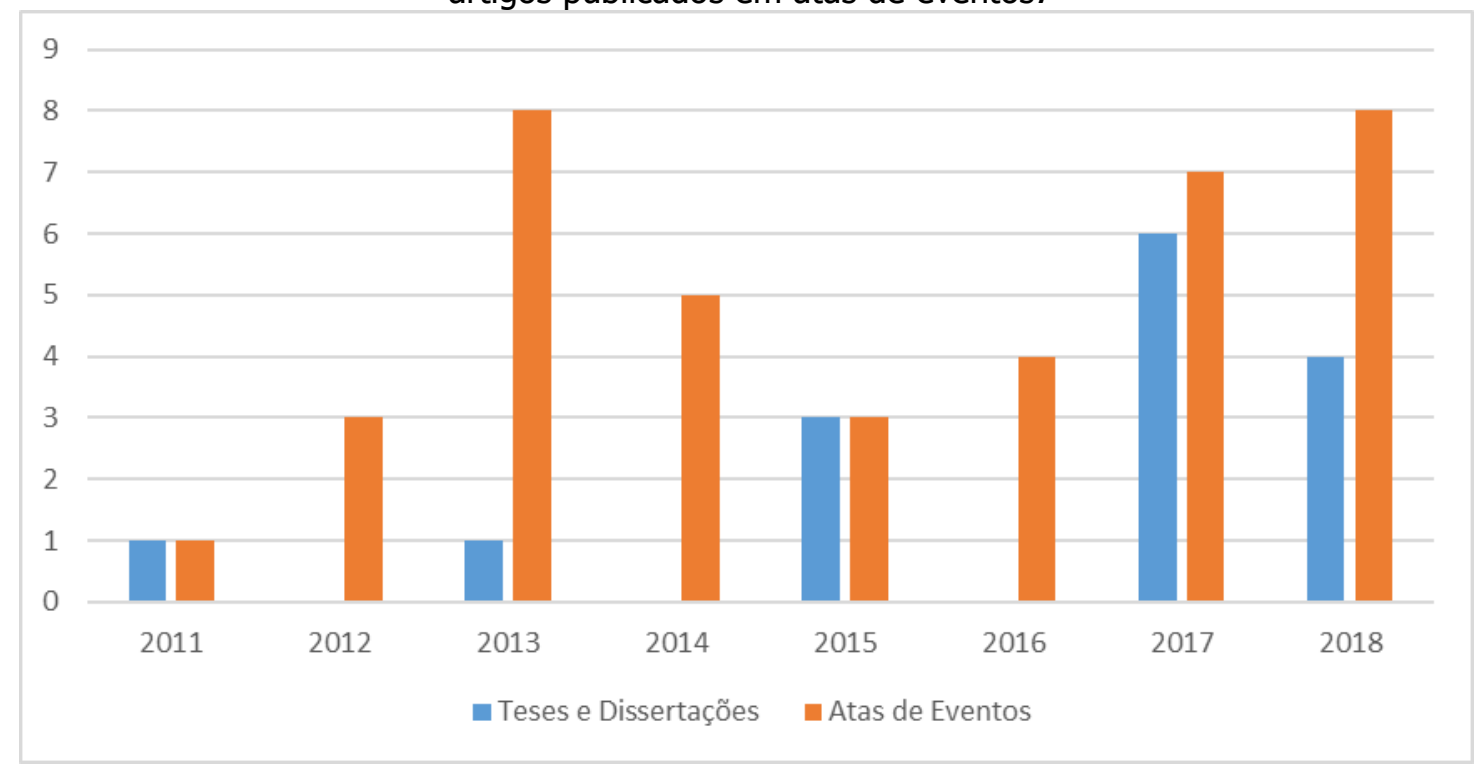

Fonte: Autores

Dentre os trabalhos, destacamos "aprendizagem no planetário: concepções e conhecimentos adquiridos por alunos do ensino fundamental" (DINIZ, DUTRA, FARIA, 2011) e "Concepções alternativas e modelos mentais sobre o movimento anual aparente do Sol: uma investigação sobre estações do ano no planetário da UFG" (ALVES e SOBREIRA, 2014) como estudos que buscam informações capazes de subsidiar a ação do planetário. O trabalho de Vilaça, Langhi e Nardi (2013) traz a discussão sobre planetários enquanto espaços formais/não-formais de ensino, pesquisa e formação de professores. Neste momento, é necessário trazer a publicação da tese "El Planetario Un Recurso Didáctico para la Enseñanza de la Astronomía" (BARRIO, 2002) que, embora tenha sido publicada no exterior, orienta muitos dos trabalhos mencionados anteriormente.

Novamente, restringimos ainda mais a incrível diversidade de pesquisas que podem ser desenvolvidas em um planetário, mantendo o foco em trabalhos que contribuam para a pesquisa sobre a criação de sessões. Aqui, trazemos os trabalhos apresentados no SNEA por Romanzini (2012), "Construção de uma sessão de cúpula e avaliação da mesma por alunos do ensino médio", por Freitas, Germano e Aroca (2013), "Proposta de etapas para a construção de uma sessão de cúpula para público geral" e por Eugênio (2014), "A narrativa dos mitos associados às constelações como forma de enriquecer a aprendizagem nas sessões do planetário do museu de ciências naturais da PUC Minas". Estes trabalhos trazem não apenas contribuições para a produção e avaliação de sessões de planetário, como agregam valor ao inserir alunos de ensino médio na construção e avaliação da sessão ou, até mesmo, propondo um roteiro a ser seguido por quem deseja desenvolver sessões de planetário.

Apesar do esforço e da importância do trabalho, Freitas, Germano e Aroca (2013) se detêm apenas a aspectos relacionados aos passos necessários para a produção das sessões, como: determinação do tema, levantamento bibliográfico, escrita narrativa, seleção de imagens, gravação de áudio e apresentação da sessão. Estes passos detalham apenas as etapas técnicas do trabalho, sem avaliar aspectos relacionados à aprendizagem dentro da cúpula. Na próxima sessão, apresentamos não apenas estes passos, mas também o ampliamos e inserimos critérios importantes, baseados na literatura mundial, que orientam a construção das sessões do ponto de vista da aprendizagem do público. 
Fazemos agora uma análise dos trabalhos publicados nos periódicos: Revista Brasileira de Ensino de Física (RBEF), Caderno Brasileiro de Ensino de Física (CBEF), Revista Latino-americana de Educação em Astronomia (RELEA) e Revista Brasileira de Pesquisa em Educação em Ciências (RBPEC).

Inicialmente mencionamos que não foi encontrado nenhum trabalho sobre planetários no CBEF e nem na RBEF, mas vale salientar que estamos em buscas de trabalhos cujo foco principal seja os planetários. Descartamos publicações que certamente contribuem muito para o desenvolvimento da pesquisa na área e que, em algum momento, trazem uma discussão sobre os planetários, como, por exemplo, o trabalho de Langhi e Nardi (2009). A RBPEC apresenta apenas um trabalho, de ELIAS, AMARAL, de ARAÚJO (2007), intitulado "Criação de um espaço de aprendizagem significativa no planetário do parque Ibirapuera", estando relacionado ao seu trabalho de mestrado (ELIAS, 2006).

Por fim, a RELEA traz apenas o trabalho de Almeida e colaboradores (2017), discutindo o papel do planetário no ensino sobre o Sistema Solar, lembrando que descartamos aqui trabalhos como o de Marques e Freitas (2015), que estudam as instituições de educação não-formal de astronomia no Brasil e sua distribuição no território nacional. Novamente, além de uma produção quase nula sobre planetários, não há nenhum trabalho sobre construção e avaliação de sessões de cúpula.

\section{PRODUÇÃO DA SESSÃO "UM PEQUENO PASSO"}

Inicialmente, trazemos as etapas para a construção e avaliação da sessão de planetário "Um Pequeno Passo", bem como elementos que contribuíram para a sua constituição enquanto uma sessão voltada para a educação formal de crianças das séries iniciais do ensino fundamental.

Uma busca inicial na literatura permitiu-nos ter um panorama geral sobre a construção de sessões para o planetário. Devido à escassa literatura nacional, encontramos no trabalho de Slater e Tatge (2017) as maiores contribuições para a construção de sessões e pesquisa sobre o ensino de astronomia em planetários. Este é um trabalho fundamental para aqueles que desejam desenvolver pesquisas envolvendo a temática de planetários. Não nos deteremos nesta etapa, pois já discutimos anteriormente um pouco sobre a produção de pesquisas na área.

Para a construção de uma sessão de planetário é importante seguir alguns passos como aqueles abordados por Freitas, Germano e Aroca (2013). Considerando esta como uma etapa inicial, descrevemos assim a proposta:

\section{Determinação e delimitação inicial do tema}

O tema foi definido devido a sua importância histórica, uma vez que a sessão foi produzida para celebrar os 50 anos da chegada do homem na Lua. Como objetivos de aprendizagem estão: a compreensão sobre os fenômenos das Fases da Lua, os Eclipses (lunar e solar), além de ser tratado brevemente a influência da Lua nas marés. O público alvo da sessão é formado por crianças das séries iniciais do Ensino Fundamental, que acaba por aumentar a importância da temática tratada, dado o número reduzido de sessões existentes no mercado sobre um tema que é conteúdo previsto para ser estudado por crianças deste nível escolar. 


\section{Aprofundamento do tema delimitando sua relevância científica, social e cultural}

Considerando a definição do tema e o levantamento de referências que dessem suporte científico para a sessão, foi necessário um levantamento, principalmente, com relação aos conteúdos de Astronomia Cultural, do qual destacamos os trabalhos de Lima e Figuerôa (2010) e Lima e Moreira (2005).

A sessão versando sobre a Lua nos fez buscar referências sobre a compreensão de crianças acerca de fenômenos como as Fases da Lua e Eclipses. Destas, é importante destacar os trabalhos de Iachel, Langhi e Scalvi (2008), Langhi (2009) e Darroz, Pérez, da Rosa e Heineck (2012) que falam sobre o tema, apresentando concepções espontâneas apresentadas por crianças, uma proposta de aprendizagem significativa para o trabalho em sala de aula e outra proposta para a utilização de um eclipse como atividade interdisciplinar. Todas estas características foram de grande relevância para a construção da sessão, além dos aspectos culturais, afetivos e de humor, mencionados anteriormente.

A Lua é alvo de observação desde a antiguidade, servindo de referência para a marcação do tempo (semanas e meses), determinando o período de rituais sagrados, época de plantio/colheita e iluminando as noites. Desta forma, a Lua é um tema de grande relevância social e cultural, apresentando-se como um tema de grande relevância científica, ao celebrarmos os 50 anos da chegada do homem na Lua e os 100 anos do eclipse de Sobral. Por fim, ainda incluímos a relevância educacional quando estudamos Fases da Lua e Eclipses, temas estes que deveriam ser apresentados para crianças das séries iniciais do Ensino Fundamental.

\section{Escolha da mensagem geral}

A sessão tem por objetivo deixar a mensagem de que a Lua é um astro que desperta grande interesse, desde os tempos mais remotos até o dia de hoje, sendo objeto de adoração, admiração e exploração científica.

\section{Escrita do roteiro da sessão}

Romanzini e Batista (2012) sugerem algumas possibilidades de abordagem para a escrita da sessão, usando diálogos e/ou narrativas. Entretanto, estudos apontam que o uso de personagens que discutem e argumentam durante a sessão auxilia no processo de aprendizagem dos conteúdos abordados (SUMNERS, REIFF, WEBER, 2008; SLATER, 2014). Ainda, alguns estudos apontam para 0 uso de elementos culturais, não como forma de favorecer a aprendizagem de um conceito específico, mas de atingir objetivos no campo afetivo (MEYERS, 2005). Desta forma, nosso roteiro é escrito no formato de diálogo de uma filha com os seus pais. Muito curiosa, a criança deseja aprender mais sobre a Lua e os pais, então, misturam elementos científicos com culturais em sua narrativa.

\section{Seleção de audiovisuais}

Em nosso caso, usamos um planetário digital, com projeção fulldome e poltronas dispostas para uma visão central. Também utilizamos um planetário inflável que, muitas vezes, é organizado no formato unidirecional. Desta forma, a sessão foi pensada para agradar tanto ao público que participa de sessões omnidirecionais quanto ao público que visita planetários unidirecionais. Algumas imagens que seriam tradicionalmente selecionadas pelo produtor já fazem parte do programa utilizado na produção da sessão (Nightshade). Outras imagens foram utilizadas a partir de suas fontes originais, como algumas imagens indígenas, sobre lendas ou vídeos de marés. A sonorização foi especialmente produzida pela equipe do planetário, considerando aspectos emocionais, principalmente com a 
preocupação de manter a sessão equilibrada em sua maior parte do tempo, uma vez que alguns fatores podem atrapalhar na aprendizagem (FISHER, 1998) e atingir um ápice na conquista da Lua, fortalecendo laços afetivos, conforme sugere Kantor (2009).

\title{
Apresentação da sessão de cúpula
}

É importante que a sessão passe por uma avaliação anterior a sua exibição pública. Desta forma, a sessão foi, inicialmente, apresentada para três turmas escolares, sem nenhuma inferência ao assunto no planetário ou em sala de aula, com o objetivo de avaliar unicamente os propósitos da sessão. Posteriormente, a sessão passou por uma reformulação, considerando os aspectos que serão discutidos posteriormente neste trabalho, e foi novamente apresentada para as turmas escolares, de forma contínua, com atividades de apoio (pré ou pós-sessão), que incluem ações que podem ser feitas em sala de aula, materiais de exibição no planetário e atividades a serem desenvolvidas após o retorno para a escola. Inserir a sessão dentro de um contexto de sala de aula e de atividades fora do domo são essenciais para o aprendizado (PLUMMER et. al., 2015).

\section{A sessão}

A sessão construída pretendia reunir diferentes aspectos culturais com a chegada do homem na Lua, sendo assim, o trabalho iniciou com uma pesquisa sobre lendas e mitos acerca da Lua, suas fases e eclipses. Descrevemos a seguir, um pouco das culturas utilizadas para a construção desta sessão.

\section{Fases da Lua}

A sessão inicia fazendo uso de uma lenda contado por Germano Afonso (2009) da seguinte forma:

\begin{abstract}
O etnólogo alemão Theodor Koch-Grünberg, por exemplo, no início do século XX, recolheu com os taurepangs, de Roraima, também conhecidos como taulipangs e pemons, o seguinte relato sobre a Lua e suas duas mulheres: "Kapei, a Lua, tem duas mulheres, ambas chamadas Kaiuanog, uma no leste, a outra no oeste. Sempre está com uma delas. Primeiro ele vai com uma, que lhe dá muita comida, de forma que se torna cada vez mais gordo. Então a deixa e vai com a outra, que lhe dá pouca comida e ele emagrece cada vez mais. Depois se encontra novamente com a outra, que o faz engordar, e assim por diante. A mulher do leste briga com o marido por ciúme. Ela Ihe diz: 'Vá para junto da outra. Então ficas outra vez gordo. Comigo não podes engordar'. E ele vai para junto da outra. Por isso as duas mulheres são inimigas e ficam sempre separadas uma da outra" (AFONSO, 2009, p. 75).
\end{abstract}

Esta lenda é narrada na sessão, enquanto a Lua é apresentada mudando de fases, de acordo com os períodos em que Kapei está com cada uma de suas esposas.

\section{Kaingang}

A mitologia Kaingang é apresentada de forma que sua tribo é dividida em dois clãs, os Kamé e os Kayrú. Enquanto os Kamé são filhos do Sol e, por isso, tem características específicas, os Kayrú são filhos da Lua, assim como diversos animais e plantas também tem origem Kamé e Kayrú. Este fato é apresentado na sessão para mostrar como a Lua possui muita influência na nossa vida terrestre, aparecendo como uma entidade de grande importância em diversas culturas. Nesta etapa da sessão, foram utilizadas músicas originais dos Kaingang.

\section{Tupi-Guarani}

Os Tupis nos contam que existem 3 deuses superiores, o Sol, criador do reino animal, a Lua, criadora do reino vegetal e Rudá, responsável pela reprodução. Apresentamos este fato e elencamos os deuses 
subordinados à Lua, muito conhecidos em nossas lendas: saci-cererê, m'boi-tatá e curupira, todos conhecidos como protetores das matas. A sessão contou com uma canção original Guarani nesta etapa.

\section{Eclipse Lunar Chinês}

A mitologia chinesa apresenta diferentes versões para falar dos eclipses solar e lunar. Escolhemos para apresentar na sessão, a versão que fala que existe um dragão no céu e que, por vezes, aparece para devorar a Lua. Uma versão similar aparece na mitologia dos índios brasileiros onde uma onça devora a Lua. A sessão apresentou um dragão voando enquanto a Lua ia sendo eclipsada e, logo em seguida, o dragão desaparece enquanto o eclipse se encaminha para a etapa final.

\section{História da Ciência}

Também utilizamos a história da ciência como tema de articulação, uma vez que o ano de exibição da sessão é marcante para o desenvolvimento da ciência, quando contados 50 ou 100 anos atrás. Em 1919, Sir Arthur Eddington realizava sua expedição para Sobral-CE, com o objetivo de coletar dados capazes de comprovar a Teoria da Relatividade Geral, proposta por Albert Einstein, em 1911. Já em 1969, encontramos uma grande motivação histórica para a sessão, a chegada da missão Apollo 11 ao solo lunar. Como estudos indicam que muita emoção pode atrapalhar na compreensão dos fenômenos explicados (FISHER, 1998), optamos por colocar o ápice da sessão no seu final. Neste momento, utilizamos trechos originais da missão Apollo 11, mesmo que em inglês e com ruído, para ambientar a viagem. Abrimos mão de qualquer explicação mais aprofundada, pois o enfoque era despertar o lado afetivo/emocional das crianças, acompanhando de perto a missão do "lift-off", passando pelo "the eagle has landed" e chegando finalmente ao "This is a small step for a man, but a giant leap for the mankind".

\section{Teorias de Aprendizagem}

Tendo a sessão construída um forte apelo educacional, cabe também discutir as teorias de aprendizagem que podem ser associadas à ela. Ainda que a filosofia de trabalho aqui destacada não alimente explicitamente a pesquisa conduzida, com uma coleta, levantamento de hipóteses e análise de dados exclusivamente direcionada a essa questão, essa discussão torna-se relevante sob diversos aspectos, das quais podemos destacar: (1) a conscientização das ideias educacionais das sessões que devem servir de orientação nos atendimentos ao público e nos materiais de apoio associados; (2) a compreensão do próprio espaço do planetário como meio de educação e difusão científica, destacando as suas potencialidades; (3) compreensão do papel do planetário também no desenvolvimento do indivíduo, como cidadão e ser social.

A sessão "Um Pequeno Passo" ao agregar histórias míticas com o discurso científico sobre um mesmo fenômeno, apresentando primeiro a versão mais fantasiosa, remete aos preceitos de Georges Snyders (1988). O filósofo e pedagogo francês pregava que era preciso valorizar o que ele chamava de cultura primeira das crianças que, de acordo com Snyders (1988):

Há muitas alegrias que não têm necessidade do sistemático - Há formas de cultura que são adquiridas fora da escola, fora de toda autoformação metódica e teorizada, que não são o fruto do trabalho, do esforço, nem de nenhum plano: nascem da experiência direta da vida, nós a absorvemos sem perceber; vamos em direção a elas seguindo a inclinação da curiosidade e dos desejos; eis o que chamarei de cultura primeira. (SNYDERS, 1988, p. 23) 
Essa cultura não sistematizada, que se formaria naturalmente pela vivência, traria prazeres mais imediatos e reais, porém, mais rasos e fugazes. De acordo com Snyders (1988), o papel da educação seria a de se amparar inicialmente nessa cultura primeira em um processo que ele chamava de ruptura-continuidade; ruptura, porque essa primeira cultura traria um desejo por um conhecimento mais profundo e sofisticado, ainda que mais difícil; e continuidade porque, mesmo ante a necessidade de se aprofundar, a cultura primeira ainda faria parte da identidade da criança que não poderia ser negligenciada.

Esse processo levaria os estudantes a um conhecimento mais profundo, complexo, pautado em um prazer mais tênue, porém, mais duradouro. Esse conhecimento, chamado por Snyders (1988) de cultura elaborada, corresponderia ao conhecimento sistematizado no qual as instituições educacionais desempenhariam um papel fundamental em seu desenvolvimento.

A sessão "Um Pequeno Passo" traz justamente esse movimento, da cultura primeira, representado pelos mitos e histórias fantasiosas que produzem aquele primeiro encantamento e curiosidade que pautam um saber que facilmente se aloja na memória, para posteriormente ser contrastado com a cultura elaborada, o discurso científico, mais sólido, complexo e abrangente, que envolve um esforço intelectual e um saber mais profundo.

"Um Pequeno Passo" também evidencia alguns aspectos da Astronomia, em especial a sua divulgação em planetários, da teoria do psicólogo americano Howard Gardner (1983; 1999) que refutava a ideia vigente de "inteligência"; qualidade esta normalmente atribuída a pessoas com bom raciocínio lógico e/ou facilidades linguísticas. Segundo, Gardner (1983), essas duas habilidades, ainda que essenciais, não abarcam todo o poderio e complexidade das habilidades humanas. Sendo assim, ele propõe que o termo "inteligência" seja expandido, englobando outras habilidades mentais, estabelecendo inicialmente cinco outras inteligências (além da lógica e da linguística): a interpessoal (capacidade de socializar), a intrapessoal (capacidade de compreender a si mesmo), a espacial (noção de orientação), a cinestésica (mais associada à coordenação motora) e a musical, incluindo posteriormente mais outras duas (GARDNER, 1999), a existencial (ligada à compreensão do ser em seu mundo de um ponto de vista filosófico e espiritual) e a naturalista (capacidade de compreender a natureza e seus padrões).

As sessões de planetário trabalham muitas dessas inteligências e, embora pareçam óbvias depois que são ditas, dificilmente são pensadas como uma forma de ensino, sendo tratadas ou como parte do entretenimento, de modo inconsciente ou simplesmente ignoradas.

Em um planetário, a inteligência espacial pode ser trabalhada primeiro pelo modo como apresenta as suas projeções, de modo imersivo, normalmente idealizado para preencher todo o campo visual. Segundo, porque compreender muitos dos fenômenos da Astronomia requer uma capacidade de se projetar em outros lugares, compreender posições relativas e entender movimentos conjugados. As fases da Lua e o eclipse são emblemáticos: para compreender por que vemos a Lua ora crescente, ora cheia e ora minguante e para entender por que ocorrem os eclipses é necessário conseguir visualizar a disposição tridimensional da Terra, do Sol e da Lua e como um observador na Terra enxerga os astros celestes em cada situação específica.

Ao final da sessão de "Um Pequeno Passo", o Saturn V é lançado, se desacopla no espaço e pousa na Lua. Essa sequência de cenas busca atingir a inteligência existencial, trazendo aquele inexplicável e paradoxal enlevo que sentimos quando pensamos que o homem, e todo o seu conhecimento 
científico, já conseguiu alcançar a Lua, mas que, ainda assim, diante de um universo infinitamente grande, corresponde a uma ínfima parte de tudo que sabemos existir.

"Um Pequeno Passo" tem uma trilha sonora que busca majorar os efeitos visuais e os conceitos trabalhados na narrativa, dando-Ihes uma carga emotiva, ao mesmo tempo que, ao utilizar uma música típica das culturas Kaingang e Tupi, busca explorar uma estética intercultural. Assim, ainda que a trilha sonora possa parecer como parte unicamente do entretenimento, do ponto de vista das Inteligências Múltiplas, há também uma componente educacional na qual se valoriza a inteligência musical.

\section{METODOLOGIA DA PESQUISA}

Em um estudo caracterizado como quanti-quali, buscamos avaliar a assimilação de conteúdos específicos sobre fases da Lua e eclipses na sessão de planetário, bem como buscamos evidenciar como os estudantes se relacionaram com a sessão, seja na percepção da Astronomia Cultural, seja emotivamente, avaliando os resultados não somente com as características da sessão, mas também com o contexto da apresentação, como o comportamento dos estudantes durante a sessão, número de expectadores, entre outros.

A pesquisa foi conduzida em dois momentos: Primeiro, buscamos avaliar os possíveis efeitos da sessão no aprendizado das crianças, seguindo o delineamento pré-experimental de Campbell e Stanley (1963) $\left(\mathrm{O}_{1} \mathrm{XO}_{2}\right)$. Para tanto, convidamos 3 turmas de segundo ano de uma escola do município para responderem a um pré-teste $\left(\mathrm{O}_{1}\right)$, após o qual, as crianças assistiram à sessão $(\mathrm{X})$ e foram submetidas ao mesmo teste $\left(\mathrm{O}_{2}\right)$.

A amostra contém 67 estudantes, contando os alunos das três turmas e desconsiderando os testes sem par (ou seja, que fizeram o pré-teste, mas não o pós-teste ou ao contrário). As idades das crianças variavam entre 7 e 9 anos.

O teste continha 22 itens avaliados, distribuídos em 15 questões (Apêndice A). A maioria das questões era de múltipla escolha (algumas com mais de uma alternativa correta), contendo também uma questão que pedia para identificar cada fase da Lua com o seu desenho correspondente e uma questão de "certo ou errado". As questões que avaliaram o aprendizado conceitual foram retiradas de testes já validados e da prova da OBA para os anos iniciais do ensino fundamental (OBA, 2019), versando principalmente sobre as fases da Lua, além de uma questão sobre o Sistema Solar e outra sobre a ocorrência de dias e noites. Além das questões conceituais, foram feitas 6 questões sobre a parte cultural da sessão, sendo duas abertas (sem resposta certa ou errada). Os resultados do préteste e do pós-teste foram então comparados, sendo a validade dos ganhos avaliados de acordo com o teste $t$ de student (SILVEIRA, 2006).

A sessão passou por ajustes de roteiro e seleção audiovisual de acordo com as respostas obtidas nesse primeiro momento. Após esses ajustes, em um segundo momento, uma nova pesquisa foi conduzida com um grupo diferente do primeiro, por meio de entrevistas que utilizaram a metodologia de lembrança estimulada. A lembrança estimulada (LE) é um termo que se refere a um grupo de métodos de pesquisa em que o sujeito é exposto a registros da atividade em que participou (FALCÃO, 2005), registros estes que podem ser dos mais variados tipos, mas que, no presente trabalho foram cenas específicas da sessão impressas em papel. As cenas funcionam como pistas que desencadeiam 
lembranças e estimulam a expressão verbal de pensamentos, crenças, concepções e comentários em geral. As entrevistas baseadas na lembrança estimulada ocorreram sempre após as sessões, em um intervalo de tempo inferior a uma hora. Foram feitas três entrevistas de LE, intermediadas pelos autores deste trabalho, com três turmas distintas que visitaram o planetário separadamente, em dias diferentes, conforme relaciona a Quadro 1. Todas as escolas são públicas e municipais. As entrevistas foram gravadas em áudio, com a captação por meio de celulares e com o consentimento dos envolvidos (ou de seus responsáveis legais). As entrevistas duraram em torno de 10 minutos.

Quadro 1 - Características dos grupos entrevistados.

\begin{tabular}{|c|c|c|}
\hline ID & Número de alunos & Idade média \\
\hline A & 15 & 10 \\
\hline B & 19 & 10 \\
\hline C & 30 & 8 \\
\hline
\end{tabular}

Fonte: Autores

Durante as entrevistas, foram mostradas 8 fotos da sessão e as crianças eram instigadas a dizer 0 que se lembravam daquelas cenas. Os temas das fotos eram:

1) Fases da Lua

2) Lua girando em torno da Terra e recebendo a luminosidade do Sol

3) Lenda dos índios Kaingang

4) Lenda do Saci Cererê

5) Lenda chinesa sobre o eclipse da Lua

6) Eclipse total do Sol em Sobral / CE

7) Explicação do Eclipse da Lua

8) Explicação do Eclipse do Sol

Foram duas entrevistas para testar o método, separando 3 alunos voluntários da turma. Essas duas entrevistas foram utilizadas primeiro como uma forma de testar o método e treinar os entrevistadores e segundo pelo ajuste da parte técnica, basicamente, como ajustar o gravador e obter um ambiente apropriado para a captação de som. Essas entrevistas não foram incluídas na análise de dados.

Diferentemente da primeira investigação, onde o foco estava mais voltado para a aquisição de conceitos, essa segunda pesquisa teve como interesse principal explorar as potencialidades da sessão, não somente no campo conceitual, mas também no campo afetivo e procedimental. Além do mais, os dados possuem maior amplitude, pois se referem não apenas à sessão avaliada, mas versa também sobre todo o trabalho realizado no planetário. Durante a realização das atividades de LE, foram também coletadas informações pela observação do comportamento dos alunos, seja nas interações entre pares, sem a participação do mediador, seja em manifestações não verbais. Uma discussão entre os pesquisadores, realizada logo após as entrevistas, com o seu registro feito posteriormente na forma escrita, constituiu um complemento às informações coletadas nas gravações.

\section{ANÁLISE DOS RESULTADOS}

\section{Delineamento Pré-Experimental}

Considerando que cada um dos 22 itens tinha o mesmo peso e sendo as respostas avaliadas binariamente (certo ou errado), foi atribuído um valor em uma escala de 0 a 10 para os testes. No 
pré-teste, a média foi de 3,81, e no pós-teste de 4,71. Portanto, um ganho médio de 0,90 . Visto que o questionário envolvia duas partes, uma conceitual e outra cultural, os resultados também são apresentados na Tabela 1 para cada uma dessas partes individualmente (cada um, também escalados de 0 a 10).

Tabela 1 - Média de toda a amostragem das notas atribuídas aos questionários.

\begin{tabular}{lccc}
\hline & Completo & Fases da Lua & Cultura \\
\hline Média Pré: & 3,93 & 3,81 & 4,15 \\
Média Pós: & 4,71 & 4,31 & 5,54 \\
Ganho médio: & 0,78 & 0,49 & 1,39 \\
\hline
\end{tabular}

Conforme pode ser percebido, em ambos os casos houve um ganho após a exibição da sessão, sendo esse ganho maior (bem como as médias pré e pós, em valores absolutos) para as questões envolvendo o céu do ponto de vista cultural. Isso seria esperado, visto que as ideias são mais simples de serem absorvidas. Considerando que o ganho segue aproximadamente uma distribuição normal (Figura 4), as chances do ganho ser decorrente do acaso em todos os casos, é menor do que $1 \%$, de acordo com o teste $t$ de student.

Figura 4 - Histograma de frequências do ganho e curva de distribuição normal esperada para a amostra do questionário completo.

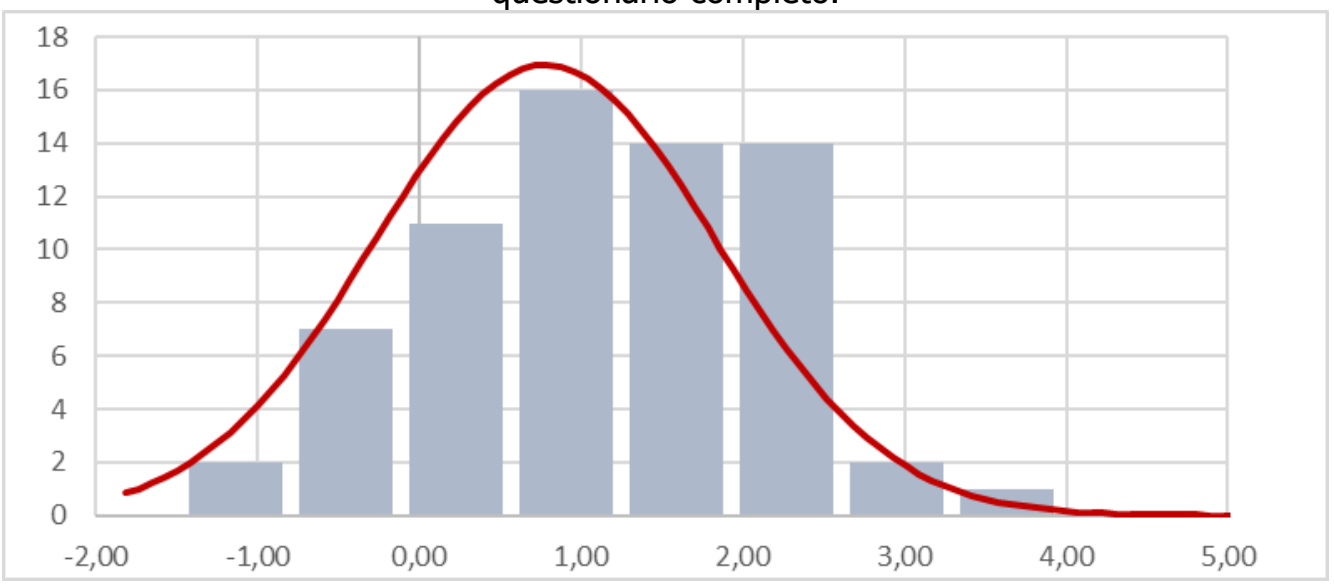

Fonte: Autores

Com relação aos conceitos das fases da Lua, avaliando os itens individualmente, a maior contribuição da sessão foi em conceitos mais gerais. O pré e o pós-teste mostraram que as crianças tiveram um melhor entendimento do que são as fases nova e cheia; porém, ainda apresentavam dificuldades de diferenciar as fases crescente e minguante. Os resultados também indicam que a razão das fases da Lua (decorrente do movimento de translação da Lua em torno da Terra) também ficou mais clara para os expectadores do "Um Pequeno Passo", com um ganho real no aprendizado, ainda que essa percepção tenha sido superficial, pois os resultados apontam que houve pouca compreensão das consequências das posições relativas do Sol, da Terra e da Lua, tanto na ocorrência de eclipses como na própria relação dessas posições com as fases da Lua.

Os testes também indicaram uma grande quantidade de respostas que justificavam as fases da Lua com o fato de que "a Lua é metade branca e metade preta" ou que era consequência "das nuvens do céu" e também mostraram que a maioria das crianças acreditava que o ciclo lunar era de apenas 1 dia. Desse modo, foram feitas alterações pontuais na narrativa e nas animações, reforçando que as fases da Lua não eram decorrentes das nuvens no céu e dizendo, explicitamente e mais de uma 
vez, que as mudanças das fases da Lua ocorrem lentamente, em um ciclo de aproximadamente 29 dias.

\section{Lembrança Estimulada}

As LEs, embora não sejam tão eficazes quanto o questionário na avaliação da aquisição de conceitos, fornecem algumas informações que outros instrumentos de medida não conseguem acessar. Verificou-se, por exemplo, que as lendas ficaram muito mais gravadas na memória das crianças, que conseguiam reconta-las com bastante precisão, além de identificar os personagens e seus papéis (proteger a floresta, engolir a Lua, etc.). Os conceitos, por outro lado, ainda que suas noções tenham apresentado melhoras, ficaram bastante dispersos sendo, no discurso, colocadas com equívocos e quase sempre com hesitação.

Inicialmente, algumas das crianças entrevistadas se apresentaram um tanto quanto tímidas por participar das entrevistas, restringindo-se a uma breve e sucinta descrição das imagens apresentadas. Com o passar do tempo e com a interferência do mediador, as crianças passaram a descrever mais o ambiente da sessão e suas emoções referentes a cada etapa, informando o que gostaram, o que entenderam ou como agiram no momento.

Em outros casos, os monitores puderam se restringir a apresentar as imagens e a turma seguiu falando e apresentando informações sobre sua relação direta com a sessão. Estes casos aconteceram principalmente quando reunimos a turma inteira de crianças menores em uma roda para conversar sobre a Lua.

Nas atividades de LE, levando em consideração não somente a entrevista, mas todo o contexto em que a sessão foi apresentada, pode-se também observar que o comportamento das turmas foi muito diverso, algumas bastante quietas e atenciosas, outras mais agitadas. O que aparece quase como regra geral é: quanto mais numerosa a turma, mais barulhenta e bagunceira; quanto menos numerosa a turma, mais concentrada ela fica na sessão. As crianças menores apresentam uma relação emotiva maior com a sessão, enquanto os mais velhos se apropriam melhor dos conceitos envolvidos na ocorrência das fases da Lua e dos eclipses.

\section{CONSIDERAÇÕES FINAIS}

Os planetários brasileiros estão em atividade há mais de seis décadas, utilizando sistemas antigos (óptico-mecânicos), sistemas digitais modernos ou híbridos. Ao longo destes anos, os planetários nacionais têm realizado um magnífico trabalho de divulgação e popularização da ciência, mas também têm deixado de lado as pesquisas relacionadas a estes espaços, em especial, a pesquisa sobre os aspectos educacionais dos planetários. Recentemente, temos visto surgir dissertações de mestrado e teses de doutorado sobre planetários, além do crescimento do número de trabalhos publicados em eventos como o SNEA, SNEF ou ENPEC. Entretanto, ainda são poucos os artigos publicados em revistas arbitradas no Brasil.

Este cenário nos coloca, por exemplo, no mesmo patamar da pesquisa americana da década de 1960. Esta avaliação nos motivou a realizar uma breve revisão do material disponível, tanto na literatura nacional quanto internacional, antes de apresentar o estudo referente à produção e avaliação da sessão de planetário "Um Pequeno Passo" por nós produzida. 
A sessão foi avaliada não apenas com relação à aprendizagem de conceitos ligados às Fases da Lua e Eclipses, mas também com relação à forma como os alunos interagiram com a sessão, seja em aspectos emotivos ou na percepção dos aspectos culturais apresentados. Para isso, foram utilizados métodos quantitativos e qualitativos.

Os resultados trouxeram indícios de aprendizagem dos conceitos chave apresentados na sessão, bem como um forte apelo emocional ligado ao ambiente imersivo do planetário. Os aspectos culturais foram destacados principalmente pelas crianças menores.

Há ainda um grande potencial de investigação. Na percepção da equipe de trabalho, o número de alunos na sessão parece apresentar maior relevância que a faixa etária da turma. Inicialmente, a sessão foi planejada para alunos de 7 a 8 anos de idade, mas parece ser apropriada para alunos de 6 a 12 anos. Essas inferências, ainda não avaliadas por um método sistemático de coleta e análise de dados, podem constituir um ponto de investigação.

A sessão também foi apresentada no planetário inflável, que viajou para mais de 20 cidades onde também foram realizados cursos de formação para futuros professores de Geografia. Esse trabalho, também com excelentes resultados, será apresentado em outro trabalho.

\section{REFERÊNCIAS}

AFONSO, Germano. Relações Afro-indígenas. Scientifc American Brasil, Edição Especial: Etnoastronomia, p. 72-79, 2009.

ALVES, Fernando Roberto Jaime; SOBREIRA, Paulo Henrique Azevedo. Concepções alternativas e modelos mentais sobre o movimento anual aparente do Sol: uma investigação sobre estações do ano no planetário da UFG. III Simpósio Nacional de Educação em Astronomia, Curitiba, PR, 2014

BARRIO, Juan Bernardino Marqués. EI Planetario: um recurso didáctico para la enseñanza de la Astronomía. Tese de Doutorado - Universidad de Valladolid, Valladolid: 2002.

BARROS, Lucas Guimarães, LANGHI, Rodolfo. A formação de planetaristas e monitores para atividades de Divulgação da Astronomia, Planetária, v.8, p. 18-19, Dez. 2015. Disponível em: https://issuu.com/planetarios/docs/planetaria nr.8

BERGLUND, Karrie. Valorizando as Sessões ao Vivo, Planetária, v.18, p. 15-20, Jun. 2018. Disponível em: https://issuu.com/planetarios/docs/planetaria nr.18

BORGES, Thiago de Oliveira. Aprendizagem em astronomia: o desenvolvimento de uma sequência didática a partir de reflexões sobre a organização de cenas presentes no ambiente do planetário móvel da Universidade Estadual de Mato Grosso do Sul. Dissertação de Mestrado - Universidade Estadual de Mato Grosso do Sul, Dourados: 2017.

CAMPBELL, Donald, STANLEY, Julian, Experimental and quasi-experimental designs for research. Chicago: Rand McNally, 1963.

CASTELAR, Alejandro. O Planetário de Montevidéu. Planetaria, n. 0, p. 16-19, 2013.

DARROZ, Luiz Marcelo; PÉREZ, Carlos Ariel Samúdio; da ROSA, Cleci Werner; HEINECK, Renato. Propiciando aprendizagem significativa para alunos do sexto ano do ensino fundamental: um estudo sobre as fases da Lua. Revista Latino-Americana de Educação em Astronomia. n. 13, 2012. 
ELIAS, Daniele Cristina Nardo. Um projeto de intervenção nos espaços de exposições do planetário do parque do Ibirapuera. Dissertação de Mestrado - Universidade Cruzeiro do Sul, São Paulo: 2011.

EUGÊNIO, Bruno da Silva Fábio. A narrativa dos mitos associados às constelações como forma de enriquecer a aprendizagem nas sessões do planetário do museu de ciências naturais da PUC Minas, III Simpósio Nacional de Educação em Astronomia, Curitiba-PR, 2014.

DINIZ, Ana Cristina Sanches, FARIA, Peter Leroy, DUTRA, Jesica Alves Leite. Aprendizagem no planetário: concepções e conhecimentos adquiridos por alunos do ensino fundamental. VIII Encontro Nacional de Pesquisa em Educação em Ciências, Campinas-SP, 2011.

FISHER, Martin. The effects of humor on learning in a planetarium. Science Education, v. 81, n. 6, p. 703-713, 1998.

FREITAS, Radma Almeida de. Construção de uma sessão de planetário para público geral com a temática 'interações Terra-Sol. Dissertação de Mestrado, Universidade Federal do Rio Grande do Norte, Natal: 2015.

FREITAS, Radma Almeida; GERMANO, Auta Stella de Medeiros; Aroca, Silvia Calbo. UM ESTUDO DAS PESQUISAS EM ENSINO E DIVULGAÇÃO DE ASTRONOMIA EM ESPAÇOS NÃO FORMAIS DE EDUCAÇÃO NO BRASIL. In: IX Encontro de Pesquisa em educação em ciências, 2013, Águas de Lindoia. Anais do IX Encontro Nacional de Pesquisa em Educação em Ciências, 2013.

FREITAS, Radma Almeida; GERMANO, Auta Stella de Medeiros; Aroca, Silvia Calbo. Desenvolvimento de uma sessão de planetario para o público geral. In: III Simposio Nacional de Educação em Astronomia, 2014, Curitiba. Anais do terceiro simposio nacional de educação em astronomia, 2014.

GARDNER, Howard. A Inteligência - Um Conceito Reformulado. Rio de Janeiro: Objetiva, 1999.

GARDNER, Howard. Frames of mind: The theory of multiple intelligences. N.Y.: Basic, 1983.

GONÇALVES, Érica de Oliveira. Planetário, o transformador, Planetária, v.9, p. 10-11, Set. 2015. Disponível em: https://issuu.com/planetarios/docs/planetaria nr.7

HONORATA, Vanessa. O Planetário da UFSC e o céu Tupi-Guarani, Planetária, v.11, p. 13-15, Set. 2016. Disponível em: https://issuu.com/planetarios/docs/planetaria nr.7

IACHEL, Gustavo; LANGHI, Rodolfo; SCALVI, Rosa Maria Fernandes. Concepções alternativas de alunos do ensino médio sobre o fenômeno de formação das fases da Lua. Revista LatinoAmericana de Educação em Astronomia, n. 5, 2008.

KANTOR, Carlos Aparecido. Aspectos emocionais nas sessões de planetários: como categorizar? XVIII Simpósio Nacional de Ensino de Física, Vitória-ES (2009).

LANGHI, Rodolfo. Educação em astronomia e formação continuada de professores: a interdisciplinaridade durante um eclipse lunar total. Revista Latino-Americana de Educação em Astronomia, n. 7, 2009.

LANGHI, Rodolfo. O Projeto Eratóstenes Brasil. Planetária, n. 3, p.15-17, 2014.

LANGHI, Rodolfo; NARDI, Roberto. Ensino da astronomia no Brasil: educação formal, informal, não formal e divulgação científica. Rev. Bras. Ensino Fís., São Paulo, v. 31, n. 4, p. 44024412, Dez. 2009. Diponível em http://www.scielo.br/scielo.php?script=sci arttext\&pid=S180611172009000400014. 
LANGHI, Rodolfo; VILAÇA, Janer; PEREIRA, Ana Maria. Qual é o nosso papel na educação?. Planetaria. v.2, p.13 - 15, 2015.

SOARES, Leonardo Marques. Etnoastronomia, interculturalidade e formação docente nos planetários do espaço do conhecimento UFMG e do Parque Explora. Tese de Doutorado, Universidade Federal de Minas Gerais, Belo Horizonte: 2017.

LIMA, Flávia Pedroza; FIGUERÔA, Silvia Fernanda de Mendonça. Etnoastronomia no Brasil: a contribuição de Charles Frederick Hartt e José Vieira Couto de Magalhães. Bol. Mus. Para. Emílio Goeldi. Ciênc. Hum. vol.5 no.2 Belém, 2010.

LIMA, Flávia Pedroza; MOREIRA, Ildeu de Castro. Tradições astronômicas tupinambás na visão de Claude D’Abbeville. Revista da Sociedade Brasileira de História da Ciência, v. 3, n. 1, 2005.

LIMA, Marcos Gonçalves Guimarães Correia. Produção de modelos didáticos como ferramenta para a compreensão e ensino de Astronomia. Dissertação de Mestrado - Universidade Federal de Mato Grosso, Cuiabá: 2014.

MALLON, Gerald; BRUCE, Matthew. Student achievement and attitudes in astronomy: An experimental comparison of two planetarium programs. Journal of Research in Science Teaching, 19(1), 53-61, 1982.

MARANDINO, Martha, Faz sentido ainda propor a separação entre os termos educação formal, não formal e informal?, Ciênc. Educ., Bauru, v. 23, n. 4, p. 811-816, 2017.

MARTINS, Cláudio Souza. O planetário: espaço educativo não formal qualificando professores da segunda fase do ensino fundamental para o ensino formal. Dissertação de Mestrado. Universidade Federal de Goiás. Goiânia: 2009

MEYERS, Margaret. Telling the Stars: A Quantitative Approach to Assessing the Use of Folk Tales in Science Education. Dissertação de Mestrado, Department of Curriculum and Instruction, East Tennessee State University, Johnson City: 2005.

OLIVEIRA, Gesoaldo Maia de. O Ensino de Ciências em Planetários: Perspectiva Interdisciplinar sobre as Sessões de Cúpula. Dissertação de Mestrado - Universidade Cruzeiro do Sul, São Paulo: 2010.

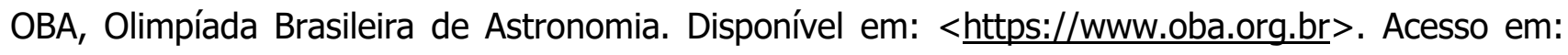
04/11/2019.

PLUMMER, Julia. Early elementary students' development of astronomy concepts in the planetarium. Journal of Research in Science Teaching, 46(2), 192-209, 2009.

PLUMMER, Julia, SCHMOLL, Shannon, Yu, Ka Chun, \& Ghent, Chrysta. A guide to conducting educational research in the planetarium. Planetarian, 44(2), 8-24, 2015.

RESENDE, Kizzy Alves. A interação entre o planetário e a escola: justificativas, dificuldades e propostas. Dissertação de Mestrado, Universidade de São Paulo, São Paulo: 2017.

RESENDE, Kizzy Alves. Em Alagoas, um planetário móvel abastece o estado. Planetária, n. 3, p. 2324, 2014.

ROMANZINI, Juliana. Construção de uma sessão de cúpula e avaliação da mesma por alunos do ensino médio. II Simpósio Nacional de Educação em Astronomia, São Paulo-SP, 2012. 
ROMANZINI, Juliana. Construção de uma sessão de cúpula para o ensino de Física em um Planetário. Orientador: Irinéa de Lourdes Batista. 2011. Dissertação (Mestrado em Ciências) Universidade Estadual de Londrina, Londrina, 2011.

ROSA, Reginaldo Guimarães. Do Big Bang ao cerrado atual: interdisciplinaridade no ensino de Ciências integrando espaços não formais. Dissertação de Mestrado - Universidade Federal de Goiás, Goiânia: 2015.

SANTOS, Giuliana Maria Miranda. Do 'astronomês' para o português: a comunicação entre astrônomos e jornalistas no Brasil. Dissertação de Mestrado - Universidade Estadual de Campinas, Instituto de Estudos da Linguagem, Campinas: 2015.

SILVA, Marcos Pedroso Barbosa. Ensino de Astronomia na educação básica na cidade de Santo André: uma parceria entre planetário e escola. Dissertação de Mestrado - Universidade de São Paulo, Instituto de Astronomia, Geofísica e Ciências Atmosféricas, São Paulo: 2017.

SILVEIRA, Fernando Lang. Determinando a Significância Estatística para as Diferenças entre Médias. In: Seminários sobre Métodos Quantitativos, Porto Alegre, Instituto de Física da UFRGS, 2006.

SLATER, Timothy. How Much Louder Do I need to Turn up the Soundtrack Before They Learn? A Cognitive Science Perspective on Memory in the Planetarium. Great Lakes Planetarium Association, Conference Proceedings, Muncie, Indiana, October, 2014.

SLATER, Timothy, TATGE, Coty. Astronomy Education Research in the Planetarium. Berlin: Springer, 2017.

SNYDERS, Georges. A alegria na escola. São Paulo: Manole, 1988.

Sumners, Carolyn; Reiff, Patricia; Weber, Wolfgang. Learning in an immersive digital theater. Advances in Space Research, 42. pp. 1848-1854, 2008.

Türk, Cumhur; Kalkan, Hüseyin. The Effect of Planetariums on Teaching Specific Astronomy Concepts. Journal of Science Education and Technology, 24, 1-15, 2015.

VARELLA, Irineu Gomes. Um Planetário para São Paulo. Planetaria, n.0, p. 20-22, 2013.

VIEIRA, Fernando. O primeiro planetário moderno. Planetária, n. 0, p. 10-13, 2013.

VILAÇA, Janer; LANGHI, Rodolfo; NARDI, Roberto. Planetários enquanto espaços formais/nãoformais de ensino, pesquisa e formação de professores. In: ENCONTRO NACIONAL DE PESQUISA EM EDUCAÇÃO EM CIÊNCIAS, 9, 2013, Águas de Lindoia. Atas... São Paulo: ABRAPEC, p.1-8, 2013.

WEBB, Mark. O planetário Adler, Planetária, n. 0, p. 14-15, 2013.

YANO, Victtor Takeshi. Formação inicial e subjetividade docente no Centro de Ciências e Planetário do Pará. Dissertação de Mestrado - Universidade Federal do Pará, Instituto de Educação Matemática e Científica, Belém: 2017.

ZIMMERMAN, Laurie; SPILLANE, Stacia; REIFF, Patricia; SUMMERS, Carolyn. Comparison of Student Learning about Space in Immersive and Computer Environments, Journal and Reviews of Astronomy Education and Outreach, 1(1), A5-A20, 2014. 


\section{APÊNDICE - TESTE APLICADO NA ANÁLISE QUANTITAIVA}

Nome: Turma:

1) A cada dia a Lua tem uma aparência (fase) diferente. Quatro dessas fases têm nomes especiais. Na figura abaixo representamos a Lua em várias fases diferentes e em sequência. A parte escura não é iluminada pelo Sol. Escreva 1 sobre a Lua Cheia, 2 sobre a Lua Quarto Crescente, 3 sobre a Lua Nova e 4 sobre a Lua Quarto Minguante.

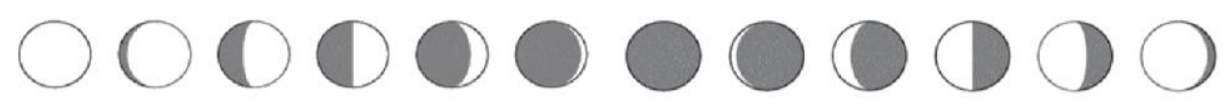

2) Escreva CERTO ou ERRADO na frente de cada frase abaixo.

A Lua tem fases porque as nuvens encobrem parte dela.

A Lua tem fases porque gira ao redor da Terra e é iluminada pelo Sol.

A Lua tem fases porque entra na sombra da Terra.

A Lua tem fases porque entra na sombra do Sol.

3) O que causa o dia e a noite?
A) A Terra gira no seu eixo
B) A Terra gira ao redor do Sol
C) As nuvens bloqueiam o Sol
D) A Terra entra e sai da sombra do Sol
E) O Sol gira ao redor da Terra
F) O Sol faz o dia e a Lua faz a noite

4) As figuras abaixo mostram como a Lua aparece em uma noite e como aparece algumas poucas noites depois. Por que a Lua muda sua aparência?
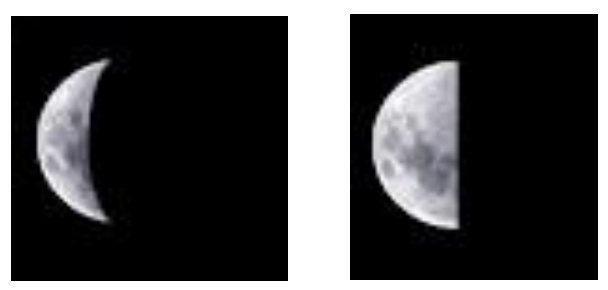
A) A Lua se move na sombra da Terra
B) A Lua se move na sombra do Sol
C) A Lua é preta de um lado e branca do outro
D) A Lua gira ao redor da Terra

5) A Lua dá uma volta na Terra em, aproximadamente:
A) Uma hora
B) Um dia
C) Uma semana
D) Um mês
E) Um ano

6) Quando a Lua parece cobrir completamente o Sol (um eclipse), a Lua deve estar em qual fase?
A) Cheia
B) Nova
C) Crescente
D) Minguante
E) Qualquer um 
7) Qual a ordem correta dos objetos, do mais próximo ao mais distante da Terra?
A) Estrelas, Lua, Sol, Plutão
B) Sol, Lua, Plutão, Estrelas
C) Lua, Sol, Plutão, Estrelas
D) Lua, Sol, Estrelas, Plutão
E) Lua, Plutão, Sol, Estrelas

8) A figura abaixo mostra a Terra e o Sol. Também mostra 5 possíveis posições para a Lua. Em qual posição a Lua deve estar quando ela é vista como na figura ao lado? Ligue a Lua até uma das posições.
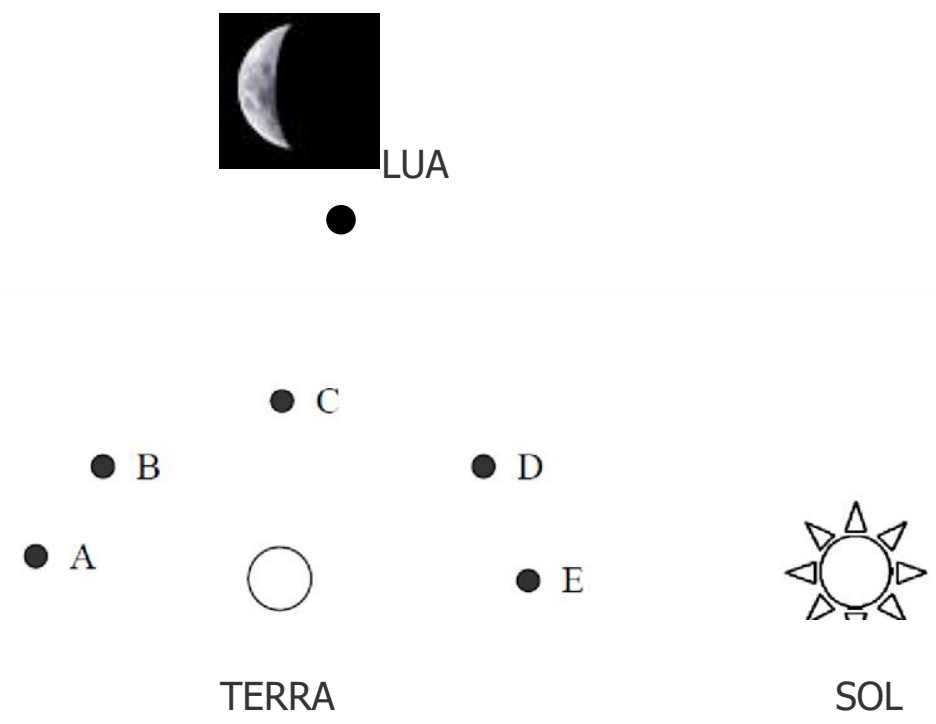

9) Você observa a Lua Cheia nascendo no início da noite. Como será a forma dela 6 horas depois?
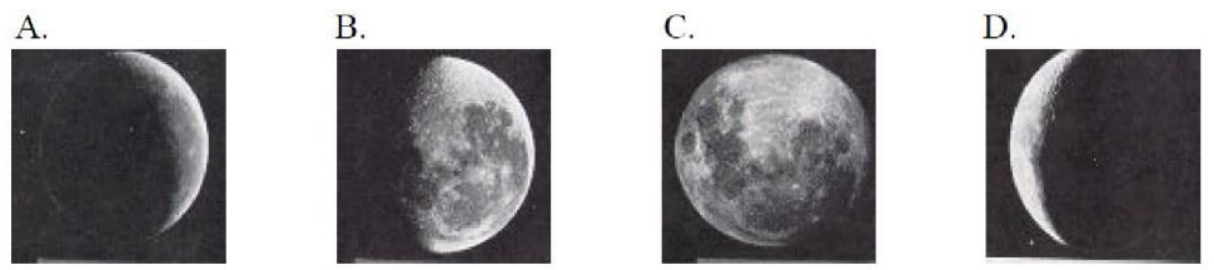

10) Quais destes existem? Você pode marcar mais que uma alternativa. Marque quantas desejar.
A) Saci Pererê
B) Curupira
C) Lobisomem
D) Morcegos

11) As lendas são:
A) histórias reais que aconteceram no passado
B) histórias reais que ainda acontecem
C) histórias que não existem e servem para diversão
D) histórias que não existem e servem para transmitir conhecimento

12) Quem são os protetores das florestas? Você pode marcar mais que uma alternativa. Marque quantas desejar.
A) Saci
B) Curupira
C) Boitatá
D) Lobisomem
E) Iara 
13) Quais conhecimentos são mais importantes? Você pode marcar mais que uma alternativa. Marque quantas desejar.
A) Ciência
B) Cultura
C) Artes
D) Matemática

14) A Lua crescente significa que:
A) O Saci cuida bem dela
B) A sua esposa lhe dá comida
C) A onça não a devorou
D) Um dragão engoliu um pedaço

15) Se a Lua desaparece do céu durante a noite é porque:
A) Ocorreu um eclipse
B) Uma onça que mora no céu a devorou
C) Um Dragão engoliu a Lua
D) O Curupira chegou

Desenhe a Terra, a Lua e o Sol. 